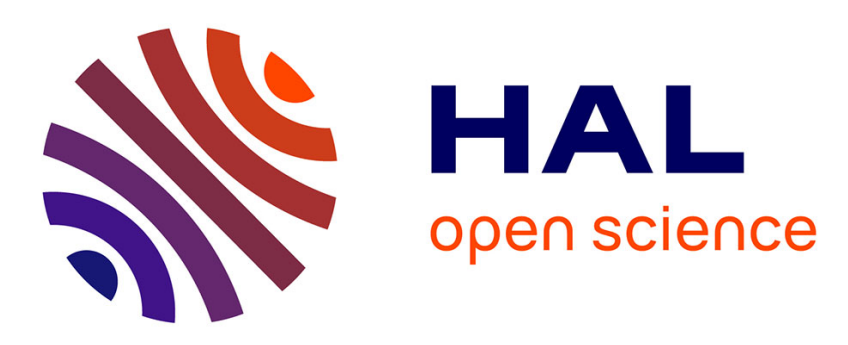

\title{
Experimental investigations concerning combined delayed ettringite formation and alkali aggregate reaction
}

Renaud Pierre Martin, Jean Claude Renaud, François Toutlemonde

\section{- To cite this version:}

Renaud Pierre Martin, Jean Claude Renaud, François Toutlemonde. Experimental investigations concerning combined delayed ettringite formation and alkali aggregate reaction. 6th International conference on concrete under severe conditions CONSEC10, Jun 2010, Mexico. 8p. hal-00904253

\section{HAL Id: hal-00904253 \\ https://hal.science/hal-00904253}

Submitted on 14 Nov 2013

HAL is a multi-disciplinary open access archive for the deposit and dissemination of scientific research documents, whether they are published or not. The documents may come from teaching and research institutions in France or abroad, or from public or private research centers.
L'archive ouverte pluridisciplinaire HAL, est destinée au dépôt et à la diffusion de documents scientifiques de niveau recherche, publiés ou non, émanant des établissements d'enseignement et de recherche français ou étrangers, des laboratoires publics ou privés. 


\title{
Experimental investigations concerning combined delayed ettringite formation and alkali aggregate reaction
}

\author{
R.-P. Martin, J.-C. Renaud \& F. Toutlemonde \\ Laboratoire Central des Ponts et Chaussées, Université Paris-Est, Paris, France
}

\begin{abstract}
Delayed Ettringite Formation (DEF) and Alkali-Aggregate Reaction (AAR) are both endogenous swelling processes that can affect concrete. They lead to a decrease of the mechanical properties, cracking and unexpected deformations and thus induce severe concerns in terms of structural integrity for affected structures. This paper describes an experimental investigation concerning the mechanical effects of DEF and AAR acting separately or simultaneously. The effect of the water supply conditions is investigated. Finally a quantitative model is proposed to account for swelling of materials affected by both DEF and AAR.
\end{abstract}

\section{INTRODUCTION}

Delayed Ettringite Formation (DEF) and Alkali-Aggregate Reaction (AAR) are both internal swelling processes that can affect concrete: these endogenous reactions lead to swelling of the material inducing macroscopic cracking, unexpected deformations and decrease of local mechanical properties and cause severe concerns regarding the structural integrity of the affected structures. DEF may affect concretes that have experienced temperatures higher than about $70^{\circ} \mathrm{C}$ (Taylor et al. 2001), allowing the sulphates to be adsorbed by the C-S-H (Divet \& Randriambololona 1998). Sulphates are later released to produce potentially expansive ettringite in the set concrete. AAR may affect concretes cast with aggregate containing reactive silica: the reaction between the alkalis of the pore solution and silica of the aggregate forms expansive gels (Dent Glasser \& Kataoka 1981).

Since DEF and AAR macroscopic effects are similar, it is difficult to identify which one is responsible of the disorders of a damaged structure (Godart et al. 2004, Ekolu et al. 2007a). Both reactions induce a map cracking of the materials and a decrease of their mechanical properties. Moreover, some investigations attest that concretes can be damaged by both reactions combined together (Johansen et al. 1993, Shayan \& Quick 1992, Thomas et al. 2008). However, it is quite difficult to diagnose which one is responsible of the distress: microscopic observations (Marusin 1994) and laboratory tests (Thomas et al. 2008) are required. This can lead to conflicting conclusions: as an example, (Tepponen \& Ericksson 1987) found that some railway sleepers were damaged by DEF whereas (Shayan \& Quick 1994) reported they were affected by AAR. Besides, both reactions seem to be chemically and mechanically coupled (Ekolu et al. 2007b, Pettifer \& Nixon 1980, Brown \& Bothe 1993, Shayan \& Ivanusec 1996). These couplings make it difficult to understand their respective deleterious contributions.

However it is necessary to deal with the affected field materials. Once a concrete structure has been diagnosed affected, it is necessary to evaluate its structural integrity and predict the evolution of the swelling process. To reach these objectives, the involved processes have to be well understood and their mechanical effects have to be assessed. An experimental program is actually carried out at the LCPC (French Public Works Research Laboratory) in partnership 
with EDF (Electricité de France). Using large scale laboratory specimens, it aims to quantify at a macroscopic scale the mechanical effects of DEF and AAR acting separately or simultaneously (Martin et al. 2008). This paper proposes an experimental quantification of DEF and DEF-AAR processes in terms of kinetics and ultimate expansion in materials stored in various water supply conditions. To explain the macroscopic expansion of the materials, a quantitative model is proposed to describe the swellings of a material affected by DEF and AAR.

\section{EXPERIMENTS}

Two concrete mixes were designed: the first one is DEF-reactive (R1) and the second one is DEF and AAR reactive (R2). Both of them are cast with CEM I 52.5 R CE CP2 NF cement (AFNOR 2000) which is a high early strength cement. Its composition is given in Table 1 . The $\mathrm{W} / \mathrm{C}$ ratio is 0.46 . To ensure the development of DEF and AAR, the alkali content of both material was increased by adding $\mathrm{K}_{2} \mathrm{O}$ in the mixing water (see Table 2). A non reactive siliceous sand was used. Two types of coarse aggregates were used: either a Non Reactive Siliceous aggregate (NRS) or an Alkali Reactive Limestone aggregate (ARL). The composition of the concrete mixes is given in Table 2. To trig DEF under controlled conditions, all specimens are heat cured in water after casting at a temperature of $80^{\circ} \mathrm{C}$ during 72 hours (Martin et al. 2008).

The investigations were performed on cylinders $(0.11 \mathrm{~m}$ in diameter and $0.22 \mathrm{~m}$ in height). Cylinders were drilled out from concrete prisms $\left(0.28 \times 0.28 \times 0.23 \mathrm{~m}^{3}\right) 28$ days after casting. During this curing period, the specimens were sealed with adhesive aluminium foils to prevent the materials from drying. The core sampling method was used not only to be representative of the operational conditions while investigating an affected structure (Multon et al. 2008, Thomas et al. 2008) but also to provide an homogenous repartition of the aggregates in the samples.

To assess the couplings between expansions and water supply conditions, the cylinders were used to perform unrestrained expansion tests under various moist exposures. For each concrete mix, specimens were stored at a temperature of $38^{\circ} \mathrm{C}$ either immersed in water (I) or in an 100 $\%$ Relative Humidity $(\mathrm{RH})$ atmosphere (H100). In this paper, the specimens are named thanks to their constitutive material and their storage condition (e.g. R1_I corresponds to the cylinders cast with R1 and immersed). They were monitored in terms of global relative mass variation by weighing and in terms of axial deformations with an extensometer (Larive 1998, Multon 2004): this device allows for each specimen to take three measurements on locations placed at 120 degrees from each other. Each measurement basis was equipped with stainless steel pins used to set the extensometer (Fig. 1).

Table 1. Cement composition (\%).

\begin{tabular}{llllllll}
\hline $\mathrm{SiO}_{2}$ & $\mathrm{Al}_{2} \mathrm{O}_{3}$ & $\mathrm{Fe}_{2} \mathrm{O}_{3}$ & $\mathrm{CaO}$ & $\mathrm{SO}_{3}$ & $\mathrm{~K}_{2} \mathrm{O}$ & $\mathrm{Na}_{2} \mathrm{O}$ & $\mathrm{Na}_{2} \mathrm{O}_{\text {eq }}$ \\
\hline 20.38 & 4.30 & 3.80 & 62.79 & 3.46 & 0.73 & 0.35 & 0.83 \\
\hline
\end{tabular}

Table 2. Composition of the concrete mixes $\left(\mathrm{kg} / \mathrm{m}^{3}\right)$.

\begin{tabular}{|c|c|c|c|c|c|c|c|c|c|}
\hline$\overline{M i x}$ & Cement & Water & Sand $0 / 2 *$ & NRS $4 / 8^{*}$ & NRS & $2 *$ ARL $4 / 7 *$ & $\mathrm{ARI}$ & *ARL 10/14* & $\mathrm{K}_{2} \mathrm{O}$ \\
\hline $\begin{array}{l}\mathrm{R} 1 \\
\mathrm{R} 2\end{array}$ & $\begin{array}{l}410 \\
410\end{array}$ & $\begin{array}{l}188 \\
188\end{array}$ & $\begin{array}{l}854 \\
797\end{array}$ & $\begin{array}{l}100 \\
0\end{array}$ & $\begin{array}{l}829 \\
0\end{array}$ & $\begin{array}{l}0 \\
114\end{array}$ & $\begin{array}{l}0 \\
29\end{array}$ & $\begin{array}{l}0 \\
843\end{array}$ & $\begin{array}{l}1.745 \\
1.745\end{array}$ \\
\hline
\end{tabular}

${ }^{*} \mathrm{~d}_{\min } / \mathrm{d}_{\max }:$ minimal and maximal particle size $(\mathrm{mm})$.

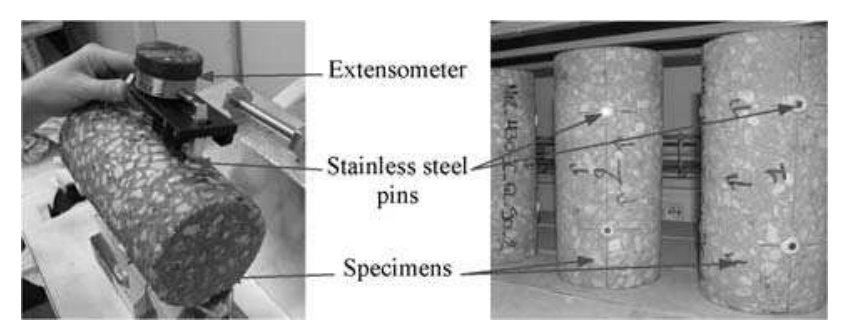

Figure 1. Concrete cylinders for unrestrained expansion test. 
To collect statistically representative data, four identical specimens were prepared for each case. Mass variations and strains evolution of each material in each water supply condition are plotted in section 3. For each case, the mean value of the four identical specimens is represented and the scatter is characterized with the standard deviation of the measured parameters represented as an error bar.

\section{RESULTS}

\subsection{Quantification of the kinetics and the magnitude of the swelling processes}

To quantify the kinetics and the magnitude of the swelling processes, the following mathematical sigmoid model is used:

$$
\varepsilon(\mathrm{t})=\varepsilon_{\infty} \frac{1-\mathrm{e}^{\left(-\frac{\mathrm{t}}{\tau_{\mathrm{C}}}\right)}}{1+\mathrm{e}^{\left(-\frac{\mathrm{t}-\tau_{\mathrm{L}}}{\tau_{\mathrm{C}}}\right)}} \cdot\left(1-\frac{\phi}{\delta+\mathrm{t}}\right) \text { with } 0 \leq \phi \leq \delta
$$

where $\tau_{\mathrm{L}}$ is the latency time (corresponding to the duration until the onset of the swellings), $\tau_{\mathrm{C}}$ is the characteristic time (corresponding to the rate of development of the swellings), $\varepsilon_{\infty}$ is the value of the strain at the end of the swelling process and $\phi$ and $\delta$ are two parameters allowing to take into account a non-horizontal asymptote. This model was developed by Brunetaud (Brunetaud 2006, Baghdadi et al. 2008) and is inspired from a model describing AAR swellings (Larive 1998, Ulm et al. 2000). A graphical representation is given in Figure 2. In this paper, the parameters are estimated by fitting the numerical estimation with the experimental data thanks to the least square method.

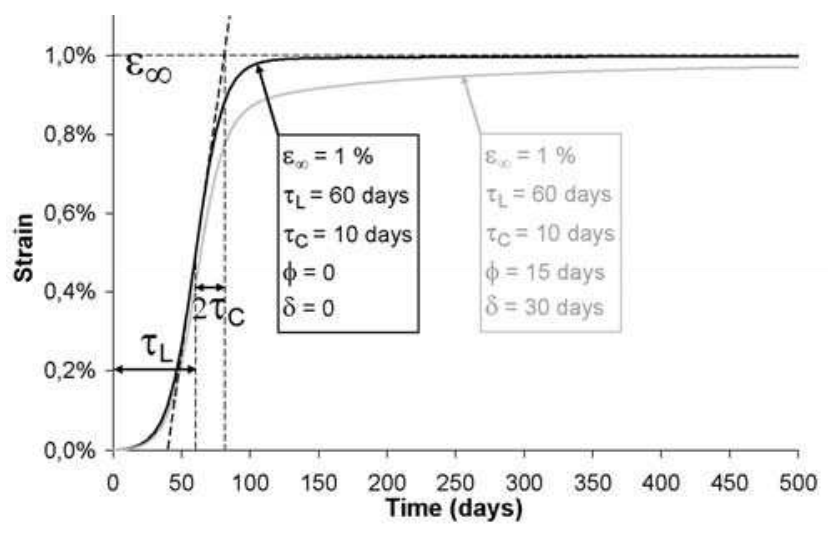

Figure 2. Mathematical model of unrestrained expansion.

\subsection{Monitoring of DEF-affected specimens}

Figure 3 represents the time evolution of strains and the mass variations of R1_I and R1_H100 specimens. The estimation of the corresponding parameters is given in Table 3 . According to this, the magnitude $\left(\varepsilon_{\infty}\right)$ and the kinetics of the DEF is shorter $\left(\tau_{L}\right.$ and $\tau_{C}$ are smaller $)$ for specimens stored in water.

Table 3. Parameters estimation for the DEF-affected specimens.

\begin{tabular}{llllll}
\hline Specimens & $\varepsilon_{\infty}$ & $\tau_{\mathrm{C}}{ }^{*}$ & $\tau_{\mathrm{L}}{ }^{*}$ & $\phi^{*}$ & $\delta^{*}$ \\
\hline R1_I & $1.58 \%$ & 11 & 83 & 18 & 120 \\
R1_H100 & $1.31 \%$ & 13 & 89 & 18 & 120 \\
\hline * in days. & & & & &
\end{tabular}



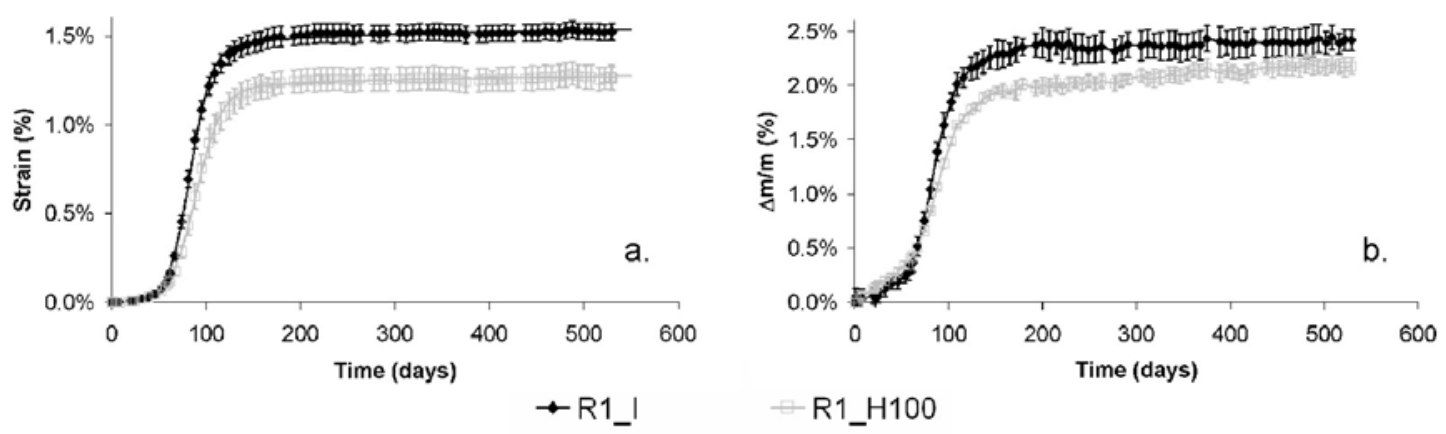

Figure 3. Monitoring of strain (a) and mass variations (b) of R1 specimens

\subsection{Monitoring of DEF-AAR-affected specimens}

Comparative evolutions of R2_I and R1_I specimens are given in Figure 4. The estimation of the parameters emphasizes that the onset of the swellings is earlier and their development is slightly faster in the AAR-DEF case since the latency time and the characteristic time are respectively shorter (see Tables 3 and 4). The magnitude of the swellings is similar in both cases. According to Figure 5, beyond a strain threshold of about $0.1 \%$, strains and mass variations are linearly related: both materials seem to have a similar hydrous behaviour during intense swelling (the slopes are similar).
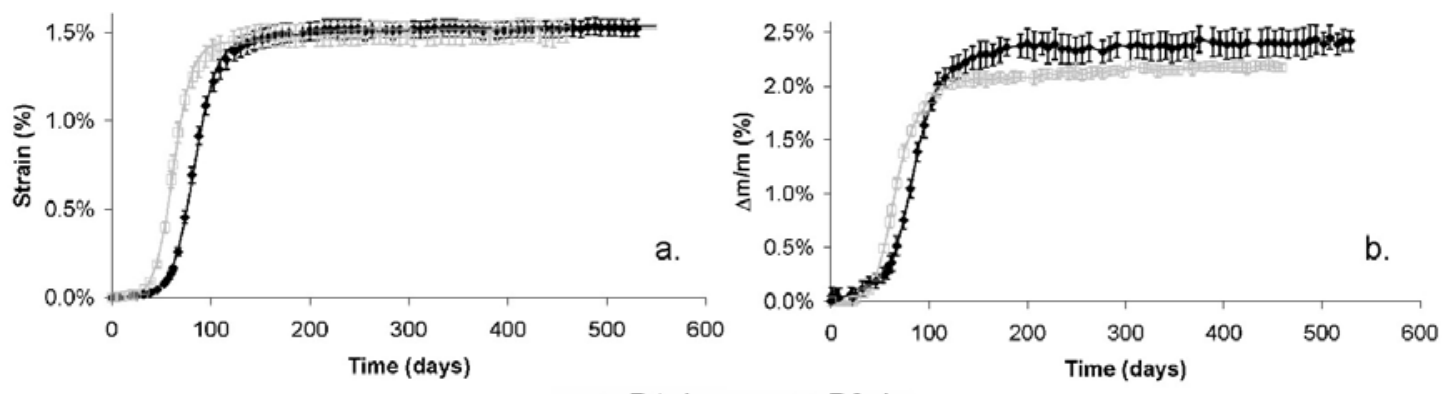

Figure 4. Comparative strain evolution (a) and mass variations (b) of R1_I and R2_I specimens

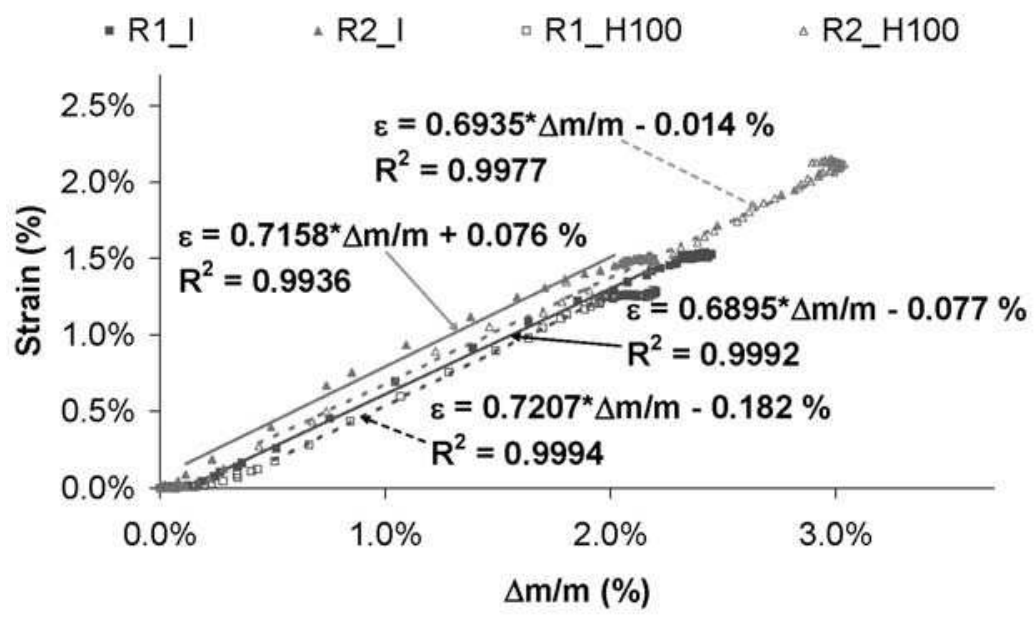

Figure 5. Relation between strains and mass variations for R1 and R2 specimens 
Table 4. Parameters estimation for DEF-AAR-affected specimens (immersed).

\begin{tabular}{llllll}
\hline Specimens & $\varepsilon_{\infty}$ & $\tau_{\mathrm{C}}{ }^{*}$ & $\tau_{\mathrm{L}}{ }^{*}$ & $\phi^{*}$ & $\delta^{*}$ \\
\hline R2_I & $1.56 \%$ & 9 & 62 & 17 & 120 \\
\hline * in days. & & & & &
\end{tabular}

Monitoring results for the R2_I and the R2_H100 specimens are given in Figure 6. As for the R1 samples, the immersed specimens exhibit earlier as well as faster development of the swellings (phases 1 and 2, see Fig. 6). However, after about 120 days of exposure, the strains of the R2_H100 specimens are growing further significantly instead of reaching a plateau as for the R1 specimens (phase 3). Finally, after a storage duration of about 350 days, the swelling processes of the R2_H100 cylinders are levelling off to a plateau (phase 4). Figure 7 shows an example of the extensive cracking of a $\mathrm{R} 2$ sample after 400 days of exposure in a $100 \% \mathrm{RH}$ atmosphere (the width of the cracks reaches about $1 \mathrm{~mm}$ ). Contrarily to the DEF case, the magnitude of the strains in moist air finally turns higher than for immersed specimens. No parameter estimation is given for this case: the numerical computations have shown that no physically representative set of parameters of Brunetaud's model can describe the experiment. Figure 5 represents the evolution of the strains as a function of the relative mass variations: the R1 and R2 specimens seem to have a similar hydrous behaviour.
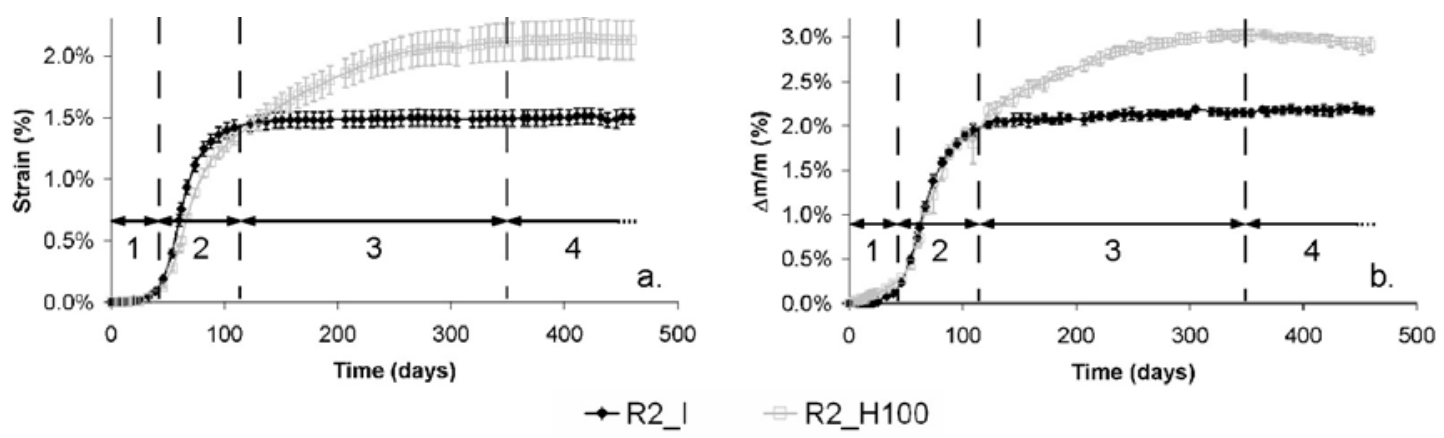

Figure 6. Strain (a) and mass (b) monitoring of R2 specimens

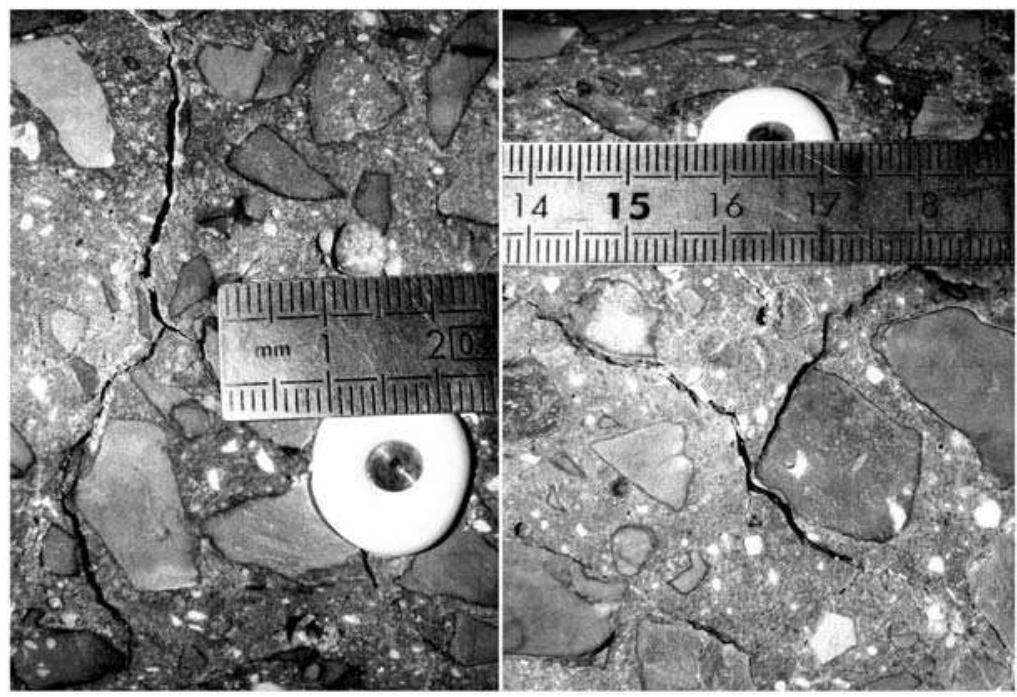

Figure 7. Cracking of a R2_H100 specimen after 400 days exposure in a $100 \% \mathrm{RH}$ atmosphere 


\section{DISCUSSION}

\subsection{Analysis of the observed swellings}

The follow-up of DEF-affected specimens has shown that the swellings become more important (faster onset and development of expansions as well as higher magnitude) when the surrounding humidity becomes higher. This result is in agreement with other researches such as (Famy et al. 2001) for example. Indeed, storage in water promotes the leaching of alkalis and thus the precipitation of ettringite (Brown \& Bothe 1993, Divet \& Randriambololona 1998). Figure 5 emphasizes that the swelling processes seem to modify the hydrous behaviour of the materials (significant increase of the mass). After the onset of the swellings, the induced microcracking could promote water ingress, further alkalis leaching and thus ettringite formation (Petrov \& Tagnit-Hamou 2004).

In the case where DEF and AAR act simultaneously, an earlier onset and a faster development of the swellings is observed: AAR could be an initiator of DEF in these experimental conditions. Namely, AAR-induced microcracking could have been initiated by the high temperature of the heat treatment at early age as mentioned by (Shayan \& Ivanusec 1996) and (Ekolu et al. 2007a) for example. It weakens the cementitious matrix and thus promotes DEF (Ekolu et al. 2007a). Moreover, this microcracking favours the water ingress in the material which could accelerate ettringite precipitation. This corresponds to a mechanical coupling between the two reactions. Besides, early AAR could have a chemical impact on the DEF processes: the formation of AAR gels implies a decrease of the alkalis and thus could promote DEF (Brown \& Bothe 1993, Divet \& Randriambololona 1998).

In the case of a DEF-AAR-affected material stored in a $100 \% \mathrm{RH}$ atmosphere, the experimental results have shown a singular behaviour that leads to further swellings instead of the expected plateau (Fig. 6). Moreover the model used to describe the DEF effects (section 3.1) turns out not appropriate in this case. To explain this phenomenon another process should thus be considered. The following mechanism is proposed: during phase 1 (see Fig. 6), a latency period is observed where no macroscopic effects are detected for specimens stored in water or in a $100 \%$ RH atmosphere. Phase 2 corresponds to an intense swelling mainly related to DEF with a higher kinetic and magnitude for the materials stored immersed than in a moist atmosphere. This leads to the development of an important network of cracks. For the concrete stored in water, the corresponding water ingress promotes the leaching of alkalis (Famy et al. 2001). On the contrary, materials in $100 \% \mathrm{RH}$ should not be massively affected by leaching since almost no liquid water is available in the porous media. During phase 3, while the swellings of immersed specimens are levelling off to a plateau since no more alkalis are available to form AAR gels, the specimens in moist air develop further swellings until all alkali reactants remaining in the matrix are used (Phase 4). This mechanism assumes that DEF acts prior to AAR. This hypothesis is in agreement with (Hanehara et al. 2008). Their corresponding results also showed that AAR delay the onset of DEF, which is not observed in our investigations. However, there is a possibility that this effect on the latency period could depend on the extent of the initial microcracking (Ekolu et al. 2007b).

\subsection{Modelling}

Based on the proposed mechanism and considering the swellings as a combination of a DEF part (Baghdadi et al. 2008) and an AAR part (Larive 1998), the following model is proposed:

$$
\varepsilon(\mathrm{t})=\varepsilon \varepsilon_{\mathrm{DEF}}+\varepsilon \varepsilon_{\mathrm{AAR}}=\varepsilon_{\infty_{-} \mathrm{DEF}} \cdot \frac{1-\mathrm{e}^{\left(-\frac{\mathrm{t}}{\tau_{\mathrm{C}_{-} \mathrm{DEF}}}\right)}}{1+\mathrm{e}^{\left(-\frac{\mathrm{t}-\tau_{\mathrm{L}_{-} \mathrm{DEF}}}{\tau_{\mathrm{C}_{-} \mathrm{DEF}}}\right)} \cdot\left(1-\frac{\phi}{\delta+\mathrm{t}}\right)+\varepsilon_{\infty_{-} \mathrm{AAR}}} \frac{1-\mathrm{e}^{\left(-\frac{\mathrm{t}}{\tau_{\mathrm{C}_{-} \mathrm{AAR}}}\right)}}{1+\mathrm{e}^{\left(-\frac{\mathrm{t}-\tau_{\mathrm{L}_{-} \mathrm{AAR}}}{\tau_{\mathrm{C}_{-} \mathrm{AAR}}}\right)}}
$$

where the parameters have the same meaning as described in 3.1. Their quantitative estimation is given in Table 5. Figure 8 compares the experimental data to the model prediction and shows the respective contribution of the DEF and AAR part. This model seems to be in good agreement with the mechanism proposed since DEF acts prior to AAR. It shows that DEF could induce further expansion during phase 3 instead of reaching an horizontal plateau. This can be 
attributed to the coupling with AAR: the formation of gels implies a decrease of the concentration of alkalis and thus further ettringite formation. Conversely, further DEF could increase water ingress and thus explain the potentially consequent magnitude of AAR swellings (Larive 1998).

Table 5. Parameters estimation for the DEF-AAR-affected specimens (100\% RH).

\begin{tabular}{lllllllll}
\hline Specimens & $\varepsilon_{\infty \_ \text {DEF }}$ & $\tau_{\mathrm{C}_{-} \mathrm{DEF}}{ }^{*}$ & $\tau_{\mathrm{L}_{-} \mathrm{DEF}}{ }^{*}$ & $\phi^{*}$ & $\delta^{*}$ & $\varepsilon_{\infty \_\mathrm{AAR}}$ & $\tau_{\mathrm{C}_{-} \mathrm{AAR}} *$ & $\tau_{\mathrm{L}_{-} \mathrm{AAR}}{ }^{*}$ \\
\hline $\mathrm{R} 2 \_\mathrm{H} 100$ & $1.54 \%$ & 9 & 65 & 57 & 113 & $0.77 \%$ & 41 & 148 \\
\hline * in days. & & & & & & & &
\end{tabular}

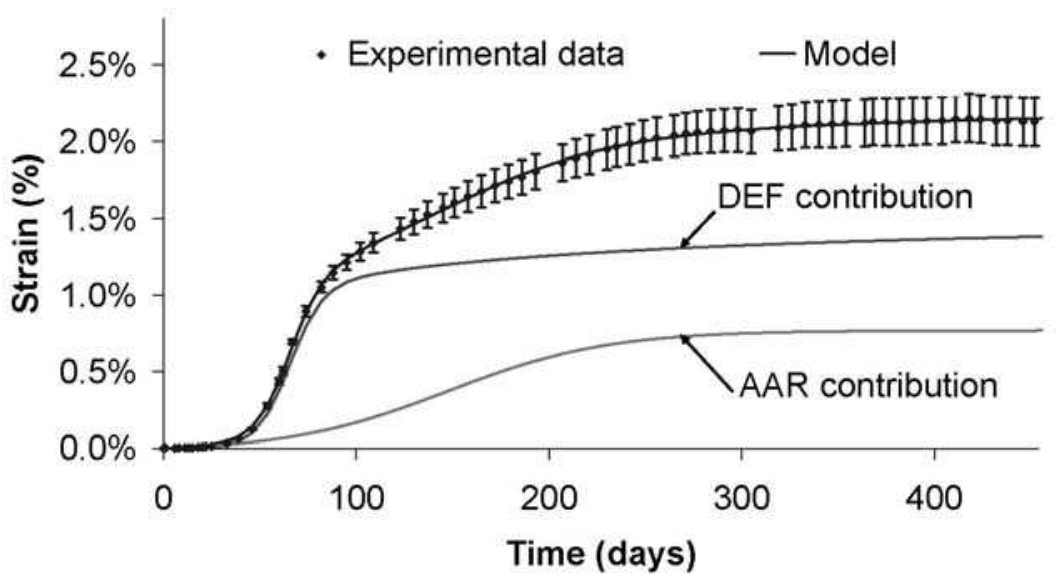

Figure 8. Modelling of the experimental results of the R2_H100 specimens

\section{CONCLUSIONS}

An experimental evaluation of the effects of DEF acting alone or combined with AAR was carried out using concrete specimens exposed to various water supply conditions at $38^{\circ} \mathrm{C}$. The role of the surrounding moisture regarding DEF was investigated and confirmed the results of many authors that DEF effects increase with the saturation of the material. In these experiments, AAR was suspected to be an initiator of swellings induced by ettringite precipitation. This has been mainly attributed to the formation of AAR gels during the heat treatment of the materials, causing microcracking and lowering of the alkalis content. For materials affected by DEF and AAR, the storage condition is a critical parameter: specimens stored in a $100 \% \mathrm{RH}$ atmosphere showed significant further expansions while levelling off to a plateau was expected. The magnitude of the swellings in this case was found much higher than for the same material immersed in water. This phenomenon was attributed to the limited leaching of alkalis in specimens stored in moist air providing reactants to form AAR gels after the development of DEF. A corresponding quantitative model was proposed. Finally, the alkalis present in the material seem to have a major effect on DEF acting alone or with AAR that has to be investigated more precisely.

To verify quantitatively the relevance of the assumptions made in this paper, further experiments are under progress at the LCPC, to assess the AAR potential of the concrete considered (which depends on the heat treatment), to quantify the rate of alkalis leaching during the storage of the specimens and finally to identify the deleterious products in the affected materials.

\section{ACKNOWLEDGMENTS}

The authors are grateful to the staff of the Structures Laboratory at LCPC and especially F.X. Barin, C. Bazin, J. Billo, M. Estivin and L. Lauvin for their determining help in the experiments and to E. Bourdarot, E. Grimal and A. Jeanpierre from EDF for their support. 


\section{REFERENCES}

AFNOR 2000. Cement - Part 1: Composition, specifications and conformity criteria for common cements, NF EN 197-1: 29 p.

Baghdadi, N., Seignol, J.-F., Toutlemonde, F. 2008. Chemo-mechanical model describing the expansion due to internal sulfate attack: numerical simulation, International RILEM Symposium on Concrete Modelling CONMOD'08, Delft, The Netherlands: 291-298.

Brown, P.W. \& Bothe, J.V. 1993. The stability of ettringite. Advances in Cement Research 18: 47-63.

Brunetaud, X. 2006. Etude de l'influence de différents paramètres et de leurs interactions sur la cinétique et l'amplitude de la reaction sulfatique interne au béton, $P h D$ thesis, Ecole Centrale de Paris: $253 \mathrm{p}$.

Dent Glasser, L.S. \& Kataoka, N. 1981. The chemistry of alkali-aggregate reactions, Cement and Concrete Research 11, 1-9.

Divet, L. \& Randriambololona, R. 1998. Delayed ettringite formation: the effect of temperature and basicity on the interaction of sulphate and C-S-H phase. Cement and Concrete Research 28: 357-363.

Ekolu, S.O., Thomas, M.D.A., Hooton, R.D. 2007a. Dual effectiveness of lithium salt in controlling both delayed ettringite formation and ASR in concretes. Cement and Concrete Research 37: 942-947.

Ekolu, S.O., Thomas, M.D.A., Hooton, R.D. 2007b. Implications of pre-formed microcracking in relation to the theories of DEF mechanism. Cement and Concrete Research 37: 161-165.

Famy, C., Scrivener, K.L., Atkinson, A., Brough, A.R. 2001. Influence of the storage conditions on the dimensional changes of heat-cured mortars. Cement and Concrete Research 31: 795-803.

Godart, B., Mahut, B., Fasseu, P., Michel, M. 2004. A guide for aiding to the management of structures damaged by concrete expansion in France, $12^{\text {th }}$ International Conference on AAR in concrete ICAAR, Beijing, China: 1219-1228.

Hanehara, S., Oyamada, T., Fukuda, S., Fujiwara, T. 2008. Delayed ettringite formation and alkali aggregate reaction, Creep shrinkage and durability mechanics of concrete and concrete structures CONCREEP 8, Ise-Shima, Japan: 1051-1056.

Johansen, V., Thaulow, N., Skalny, J. 1993. Simultaneous presence of alkali-silica gel and ettringite in concrete. Advances in Cement Research 17: 23-29.

Larive, C. 1998. Apports combinés de l'expérimentation et de la modélisation à la compréhension de l'alcali-réaction et de ses effets mécaniques, OA 28, Paris: LCPC.

Martin, R.-P., Siegert, D., Toutlemonde, F. 2008. Experimental analysis of concrete structures affected by DEF, $3^{\text {rd }}$ International Symposium on THMC coupling in geomatrials and applications GEOPROC'2008, Lille, France: 589-596.

Marusin, S. L. 1994. A simple treatment to distinguish alkali-silica gel from delayed ettringite formations in concrete. Magazine of Cement Research 168: 163-166.

Multon, S. 2004. Evaluation expérimentale et théorique des effets mécaniques de l'acali-réaction sur des structures modèles, OA 46, Paris: LCPC.

Multon, S., Barin, F.-X., Godart, B., Toutlemonde, F. 2008. Estimation of the residual expansion of concrete affected by alkali silica reaction. Journal of Materials in Civil Engineering 20: 54-62.

Petrov, N. \& Tagnit-Hamou, A. 2004. Is microcracking really a precursor to delayed ettringite formation and consequent expansion? ACI Materials Journal 101: 442-446.

Pettifer, K. \& Nixon, P.J. 1980. Alkali-metal sulfate - factor common to both alkali aggregate and sulfate attack on concrete. Cement and Concrete Research 10: 173-181.

Shayan, A. \& Ivanusec, I. 1996. An experimental clarification of the association of delayed ettringite formation with alkali-aggregate reaction. Cement and Concrete Composites 18: 161-170.

Shayan, A. \& Quick, G.W. 1992. Microscopic features of cracked and uncracked concrete railway sleepers. ACI Materials Journal 89: 348-361.

Shayan, A. \& Quick, G.W. 1994. Alkali-aggregate reaction in concrete railway sleepers from Finland, $16^{\text {th }}$ International Conference on Cement Microscopy, Duncanville, TX: 69-79

Taylor, H.F.W., Famy, C., Scrivener, K.L. 2001. Delayed ettringite formation. Cement and Concrete Research 31: 683-693.

Tepponen, P. \& Ericksson, B.-E. 1987. Damages in concrete railway sleepers in Finland. Nordic Concrete Research 6: 199-209.

Thomas, M., Folliard, K., Drimalas, T., Ramlochan, T. 2008. Diagnosing delayed ettringite formation in concrete structures. Cement and Concrete Research 38: 841-847.

Ulm, F.-J., Coussy, O., Kefei, L., Larive, C. 2000. Thermo-chemo-mechanics of ASR expansion in concrete structures. Journal of engineering mechanics 126: 233-242. 